\section{Semantic and Syntactic Fraction Understanding}

\author{
Anass Bayagaa ${ }^{a}$ Michael J. Bosséb
}

\begin{tabular}{ll}
\hline Received: & 25 September 2018 \\
Revised: & 10 December 2018 \\
Accepted: $\quad 07$ January 2019 \\
ISSN: 1307-9298 \\
Copyright @ IEJEE \\
www.iejee.com
\end{tabular}

DOI: $10.26822 /$ iejee.2019248587

\begin{abstract}
This study begins by connecting semantic elaboration with conceptual understanding and syntactic elaboration with procedural understanding in the context of fractions. Through case studies and discourse analysis, the work and communication of students in fourth through sixth grade is analyzed to determine the extent of their semantic and syntactic elaboration regarding fractions and fraction operations. Findings are that, while some students emphasized one form of elaboration over the other, some students demonstrated use of both forms of elaboration. Indeed, it is wondered if semantic and syntactic elaboration should be seen as more complementary than adversarial.
\end{abstract}

Keywords: Semantic Elaboration, Syntactic Elaboration, Conceptual Understanding, Procedural Understanding

\section{Introduction}

While researchers continue to examine students' learning of fractions (Kara \& Incikabı, 2018; Hyde, Khanum, \& Spelke, 2014; Inglis \& Gilmore, 2013; Jacob \& Nieder, 2009; Meert, Grégoire, \& Noël, 2009; Murray, Olivier, \& Human, 1996), students continue to possess limited understanding of fractions and often remain unable to adequately communicate ideas associated with fractions. Meert, Grégoire, and Noël (2009) and Murray, Olivier, and Human (1996) report specific challenges students encounter, including a lack of conceptual understanding of equality. These challenges lead to students incorrectly performing arithmetic operations on fraction and developing their own incorrect arithmetic heuristics.

Although semantics and syntax have received considerable attention in student mathematical communication, some opine that the limited consideration of student fraction understanding through these lenses is probably due to teachers themselves possessing insufficient understanding of semantics and syntax in the context of fractions (Meert, Grégoire, \& Noël, 2009; Opfer \& DeVries, 2008; Sasanguie et al., 2013). However, some researchers recognize that contextualizing fraction learning in real-world problems helps to demonstrate the semantic structure of fractions and leads to greater learning (Leibovich \& Ansari 2016; Newstead \& Murray, 1998; Opfer \& DeVries, 2008). It can be inferred that a number of factors can contribute to students gaining deeper semantic understanding of fractions. Understanding semantics and syntax may be the cornerstone to unpacking the difficulties learners encounter when learning, and performing operations on, fractions.

This study suggests that students could be aided in their learning of the principles of fractions by understanding semantics, syntax, and their relationships. The current research begins an initial dialog defining student use of semantic and syntactic elaborations in the context of fraction arithmetic and understanding.

\section{Literature Review}

Investigating the role of semantics and syntax in respect to language learning is far from novel and considering the roles of semantics and syntax in the context of mathematical communication is becoming increasingly in vogue (e.g., Meert, Grégoire, \& Noël, 2009; Opfer \& DeVries, 2008; Sasanguie et al., 2013). In the context of mathematics, particularly with fractions, many have ascribed semantics with connecting mathematics to real-world scenarios (e.g., Leibovich \& Ansari 2016; Opfer \& DeVries, 2008). In this current investigation, we will extend upon this notion and define particular fractional arithmetic and understanding as either semantic or syntactic.

Throughout the 60s, 70s, and even 90s, significant work investigated students' language of fractions (Halliday, 1975, 1993; Halliday, McIntosh, \& Strevens, 1964). While these studies extended the literature regarding students' use of language in mathematics, they led to inconsistencies in defining and identifying students' syntactic and semantic interaction with mathematics in general and fractions in particular. Subsequently, various themes have emerged in unpacking students semantic and syntactic interaction with mathematics. These include: semantic and syntactic elaborations; understanding and communication of fractions and semantics, syntax, and sequencing.

Semantic (Global and Conceptual) and Syntactic (Local and Procedural) Interactions

Kaput (1987a, 1978b) identifies two types of interactions a person can have with a mathematical representation: syntactic elaboration (interacting with a representation by directly manipulating the symbols in the representations without reference to the meaning of the idea represented) and semantic elaboration (interacting with a representation based on the features of the ideas represented, rather than the symbols themselves). In the context of representational in-

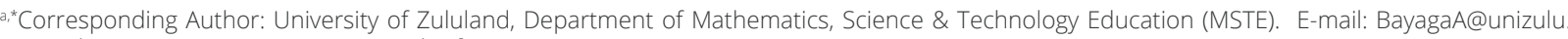
ac.za, Phone: +27 (0) 35902 6809, South Africa.

Appalachian State University, Department of Mathematical Sciences, Boone, NC, 28608-2092, USA. E-mail: bossemj@appstate.edu Office Phone: (828) 262-2862,
} 
terpretation, syntactic elaboration is akin to interpreting an expression by considering local characteristics of the expression and semantic elaboration as connecting the representation more globally to overarching ideas (Duval, 2006, Kaput, 1987a, 1987b). For example, in respect to a fraction such as $2 / 3$, a student may syntactically focus on the local attributes of the 2 , the 3 , or the division symbol or operation without semantically connecting $2 / 3$ to the global notion of rational numbers.

In a parallel manner, while local, syntactic interactions can be equated to instrumental or procedural understanding (using processes and algorithms to produce results) of mathematics, global semantic interactions hold similarities with conceptual understanding (the ability to see interconnections among ideas) (Hallett, Nunes, \& Bryant, 2010). While some have recognized elementary students difficulties with fractions concepts (e.g., Braithwaite, Pyke, \& Siegler, 2017; Bulgar, 2003; Gabriel et al., 2013; Siegler et al., 2011; Tirosh, 2000; Van Steenbrugge, Lesage, Valcke, \& Desoete, 2014), some equate this to students primarily possessing procedural knowledge of fractions and operations (e.g., Byrnes \& Wasik, 1991; Kerslake, 1986; Rittle-Johnson, Siegler, \& Alibali, 2001). Interestingly, while Kerslake (1986) has determined that some students can have success with some fraction operations using primarily procedural knowledge, Byrnes and Wasik (1991) contend that conceptual knowledge regarding fractions is the prerequisite and Hallett, Nunes, and Bryant (2010) suggest that some students rely more on procedural understanding and others on conceptual understanding. However, when students demonstrate lesser conceptual understanding and greater procedural understanding, this may limit their understanding of fractions (Van Steenbrugge et al., 2014) and lead to the development of misunderstandings (Hallett Nunes, \& Bryant, 2010; Kerslake, 1986).

\section{Communication and Procedural and Conceptual Misunders-} tanding Fractions

Based on whole number bias and other misconceptions, students' understanding and communication of fractions continues to be investigated (e.g., Bartelet, Ansari, Vaessen, \& Blomert, 2014; DeWolf, Rapp, Bassok, \& Holyoak 2014; luculano \& Butterworth, 2011; Kallai \& Tzelgov, 2009; Lyons, Price, Vaessen, Blomert, \& Ansari1, 2014; Meert, Grégoire, \& Noël, 2009; Opfer \& DeVries, 2008; Schneider \& Siegler, 2010). Research reveals that some student difficulties with fractions are born from misunderstandings with natural numbers (e.g., Siegler, Thompson, \& Schneider, 2011; Stafylidou \& Vosniadou, 2004; Van Steenbrugge et al., 2014). This is because, children's knowledge of natural numbers can inhibit later fraction learning (Siegler et al., 2011). The primary reason may be due in part to the fact that fractions are inconsistent with the counting principles, counting-based algorithms, and numerical ordering applicable to natural numbers (Stafylidou \& Vosniadou, 2004). This results in whole number bias leading to misconceptions (Van Steenbrugge et al., 2014). Additionally, the multi-dimensional nature of the fraction construct also leads to student difficulties (e.g., Charalambous \& Pitta-Pantazi, 2007; Kieren, 1976; Van Steenbrugge et al., 2014). To overcome this, fractions must be considered through interconnected subconstructs (i.e., ratio, operator, quotient, and measure) (Kieren, 1976) and the part-whole construct (Behr, Lesh, Post, \& Silver, 1983), all defined by Charalambous and Pitta-Pantazi (2007) and Van Steenbrugge et al. (2014).

Connecting to previous discussions of procedural (local and syntactic) and conceptual (global and semantic) understanding, fraction misunderstandings are generally classified as either procedural or conceptual. Whole number bias, incorrect fraction operation strategies, and divi- sion of two fractions are usually classified as procedural fraction misunderstanding and fraction equivalence and abuses of the previously mentioned subconstructs are classified as conceptual misunderstandings (Braithwaite et al., 2017; Bulgar, 2003; Charalambous \& Pitta-Pantazi, 2007; Gabriel et al., 2013; Siegler et al., 2011; Tirosh, 2000; Van Steenbrugge et al., 2014).

Misconceptions emanating from students' incorrect intuitions and informal experiences has also been one factor why learning of fractions decimals is challenging. For instance, Newstead and Murray (1998) argue that students' difficulties with division by a fraction may be due to limitations arising from their own intuitions and real-life experiences. They also argue that, when division by fractions decontextualized, the result may conflict with students' previously held notions as it can produce a quotient greater than either the dividend or the divisor. Altogether, teachers should expose learners to a variety of situations and contexts regarding division.

Altogether, the literature seems to indicate that whole-number schemes can be somewhat unsuitable for fraction conceptualization and that children's limited understanding of fractions may be born from their limited ability to communicate (interpret and produce) linguistically posed mathematical ideas. For instance, when there is a seeming lack of understanding of equality of fractions, there seems to commensurately be a limited ability to communicate ideas associated with equivalent fractions (Kolkman, Kroesbergen, \& Leseman, 2013; Leibovich \& Ansari 2016; Meert, Grégoire, \& Noël, 2009; Opfer \& DeVries, 2008; Sasanguie, et al., 2013).

\section{Semantics, Syntax, and Poor Sequencing}

Since the early 1990s, numerous studies suggest that there seem to be different reasons why children find it difficult to learn fractions. The work of Baroody and Hume (1991), Streefland (1991) and D'Ambrosio and Mewborn (1994) have chronicled the problems as poor sequencing and limited variety of fractions. Thus, limited content in the form of teaching only halves and quarters and the use of pre-partitioned manipulatives, could be contributory factors. Some studies also demonstrate that semantic alignment largely correlates with the learning of fractions (DeWolf et al., 2014; Kallai \& Tzelgov, 2009; Park \& Brannon, 2013, 2014; Sasanguie et al, 2013; Schulze, 2016; Schleppegrell, 2007; Thwaite, 2015; Turkan, de Oliveira, Lee, \& Phelps, 2014; van Lier \& Walqui, 2012). Both children and adults find it easier and more natural to solve or construct semantically-aligned rather than misaligned word problems (DeWolf et al., 2014). Some studies have explored grades four and six students' concept and operation understanding through success and misconceptions (DeWolf et al., 2014; Kallai \& Tzelgov, 2009; Park \& Brannon, 2013; Schulze, 2016; Schleppegrell, 2007; van Lier \& Walqui, 2012). Summarily, research suggests that entities in a problem situation evoke semantic relations.

\section{Objective of the study}

Thus far, there is sufficient reason to suggest that recognizing students' semantic versus syntactic understanding of fractions may be key in unraveling the difficulties in learning fractions. Contextualized in this recognition, the current study investigates student work and communication regarding fractions and arithmetic operations on fractions and seeks to interpret their understanding from the lens of semantic and syntactic understanding of fractions.

\section{Methodology}

In order to gain insight into student understanding of fractions in the form of semantic versus syntactic understan- 
dings, the research methodology employed in this study are case studies and discourse analysis (Bogden \& Biklen, 2003; Creswell, 2003; Goldin, 2000; Miles \& Huberman, 1994; Wodak \& Meyer, 2009). This study sought to explore, fourth-, fifth-, sixth-, and seventh-grade student understating of fractions and decimals through the lens of semantic (global and conceptual) and syntactic (local and procedural) elaboration (Braithwaite, Pyke, \& Siegler, 2017; Bulgar, 2003; Byrnes \& Wasik, 1991; Gabriel et al., 2013; Kaput, 1987a, 1987b; Kerslake, 1986; Hallett, Nunes, \& Bryant, 2010; Rittle-Johnson, Siegler, \& Alibali, 2001; Siegler et al., 2011; Tirosh, 2000; Van Steenbrugge, et al., 2014). Seven distinct scenarios of student-student or student-teacher interactions regarding various contexts of fraction and decimal understanding were investigated. These included:

Scenario 1: Sixth grade student and teacher (ten years teaching with 4 years in this grade with a master's degree in education) discussing fraction simplification.

Scenario 2: Fourth grade student and teacher (five years teaching in the same grade) comparing fraction magnitude.

Scenario 3: Fifth grade student and teacher (seven years teaching all in the same grade with a master's degree in education) discussing equivalent fractions equal to 1 .

Scenario 4: Sixth grade student and teacher (in her first year if teaching) discussing a technique for fraction addition.

Scenario 5: Sixth grade student and teacher (thirteen years teaching with seven years in this grade) discussing the lowest form of a fraction.

Scenario 6: Four seventh-grade students discussing simplifying fractions.

The case study aspect focused on participants who were students in various classrooms in the southeastern part of the United States. The discourse analysis focused on each transcript which was a subset of a larger set of transcripts recording the interactions of students and teachers in the context of fractions and decimals. Each recorded in teraction took place in the students' and their respective teachers' regular classroom setting in the southeastern United States. These schools and teachers were selected singularly for their convenience to the researcher and participating teachers. Videotaping occurred on days when the teachers were anticipating covering the respective fraction and decimal topics.

To unpack meaning from the transcripts (Creswell, 2003), the data was systematically analyzed (Bogden \& Biklen, 2003). Videotapes capturing student work and communication were transcribed. Discourse analysis (Wodak, 2009; Wodak \& Meyer, 2009) was employed to investigate student understanding; this was completed both by individual researchers and then again by the team of researchers. The themes of semantic and syntactic elaborations were characterized and behaviors connoting such elaborations were coded in the transcripts. Check-coding (Miles \& Huberman, 1994) was employed (the coding of each individual researcher was considered by the team of researchers, differences were reconciled, and refinements were made) to allow researchers to reach consensus on the analysis of all transcripts.

\section{Results and Initial Analyses}

In this section, we provide portions of transcripts together within initial analysis of semantic versus syntactic elaboration through seven scenarios of student-teacher and student-student interactions.
Scenario 1: Sixth grade student and teacher (ten years teaching with 4 years in this grade with a master's degree in education) discussing fraction simplification.

Student: A ratio is just a fraction of fractions.
Teacher: What do you mean?
Student: Well, a fraction is a part to a whole. And a ratio
is a part to a part.
Teacher: Yes? Can you give me an example?
Student: Well let's say that we have 5 boys and 7 girls in
a class. The ratio of boys to girls is 5 to 7 . But that is a part to
a part.

Teacher: Right? But, then, how does that make it a fraction of fractions?

Student: Well, of the class is boys and of the class is girls. These are both part to whole fractions. So, if I set them up as a fraction of fractions, I get:

$$
\begin{aligned}
& \frac{\frac{5}{12}}{\frac{7}{12}}=\frac{5}{12} \div \frac{7}{12}=\frac{5}{12} \times \frac{12}{7}=\frac{5}{12} \times \frac{12}{7}=\frac{5}{7} \\
& \text { Teacher: So, you get the fraction } \frac{5}{7} ? \\
& \text { Student: Well, kinda. I get the ratio } \frac{5}{7} \text { or } 5 \text { to } 7 . \\
& \text { Teacher: But is that a ratio or a fraction? } \\
& \text { Student: It is a ratio. }
\end{aligned}
$$

Teacher: I see what you mean that a ratio is a fraction of fractions. But you are starting with fraction and performing operations on fractions. How does it become a ratio?

Student: I'm not really sure. But it does work.

Teacher: Where did you see this idea?

Student: I came up with it myself.

This student's articulations seem to demonstrate none of the previously mentioned fraction misunderstandings classified as either semantic (conceptual) or syntactic (procedural) (Braithwaite et al., 2017; Bulgar, 2003; Charalambous \& Pitta-Pantazi, 2007; Gabriel et al., 2013; Siegler et al., 2011; Tirosh, 2000; Van Steenbrugge et al., 2014). While the respondent's interpretation of a ratio as a fraction of fractions is somewhat irregular, respondent demonstrates a sufficiently sophisticated understanding of fractions and ratios that respondent interconnects the ideas without having previously received instruction regarding such. Indeed, Kieren (1976) and others have noted that recognizing fractions through the subconstruct of ratio is a component of conceptually understanding fractions. Thus, this student seems to primarily demonstrate semantic elaboration regarding fractions and decimals.

Scenario 2: Fourth grade student and teacher (five years teaching in the same grade) comparing fraction magnitude.

Teacher: Which is greater, $\frac{2}{5}, \frac{3}{5}$, or $\frac{2}{4}$ ? And why?

Student: Well, $\frac{3}{5}$ has the biggest top number?

Teacher: So, is $\frac{3}{5}$ the greatest number? Is that all that mat-
ters?

Student: No. $\frac{2}{4}$ has the smallest bottom number. 
Teacher: So is $\frac{2}{4}$ the greatest number?

Student: I think that I want the number with the biggest top and the smallest bottom. But that is two different numbers. know that is bigger than. And I know that $\frac{3}{5}$ is bigger than $\frac{2}{5}$. But, I'm stuck between $\frac{2}{4}$ and $\frac{3}{5}$.

Teacher: Do you have any ideas on how to figure that out?

Student: I could make pictures.

Teacher: Ok.

Student: (Show circles shaded of $\frac{2}{4}$ and $\frac{3}{5}$.) I think that is a little bit bigger. But not much. So, must be the biggest.

This student attempts to compare the magnitude (or measurement) of fractions, which could be a semantic task by syntactically isolating the numerators and then the denominators and not semantically considering the entirety of the fractional representation. The respondent does not seem to consider the fraction as a ratio, operator, quotient, and measure (Kieren, 1976), or as a part-whole construct (Behr et al., 1983), all associated with semantic, conceptual understanding (Charalambous \& Pitta-Pantazi, 2007; Van Steenbrugge et al., 2014). However, respondent work does seem to exemplify whole number bias, accepted as syntactic, procedural understanding.

Scenario 3: Fifth grade student and teacher (seven years teaching all in the same grade with a master's degree in education) discussing equivalent fractions equal to 1 .

Teacher: Is $\frac{31}{31}$ greater than $\frac{9}{9}$ ?

Student: Yes.

Teacher: Why?

Student: 31 is bigger than 9 .

Teacher: But it is not 31 and 9. It is $\frac{31}{31}$ and $\frac{9}{9}$.

Student: I know.

Teacher: So, what are the parts and the wholes?

Student: For $\frac{31}{31}$, the whole is 31 and the parts are 31. For $\frac{9}{9}$, the whole is 9 and the parts are 9 .

Teacher: So, for $\frac{31}{31}$ you have all the parts of the whole and for $\frac{9}{9}$ you have all the parts of the whole. So, in both cases, you are using all of the whole.

Student: But there is more of the whole for $\frac{31}{31}$.

Teacher: But aren't each of the 31 parts of the whole smaller than each of the 9 parts of the whole?

Student: Yes. 31 parts would be very small.

Teacher: But you would be using all of them.

Student: The 9 pieces would each be bigger.

Teacher: And, again, you would be using all of them.

Student: But 31 parts is still a lot more than 9 parts. So, $\frac{31}{31}$ has to be bigger.
This student seems to syntactically employ whole number bias and measurement, as she focuses on the numerator of each fraction rather than on the semantic constructs of ratio, operator, and quotient (Behr et al., 1983; Charalambous \& Pitta-Pantazi, 2007; Kieren, 1976; van Steenbrugge et al, 2014). However, respondent communication demonstrates some incomplete notions of the part-whole construct and fraction equivalence, two ideas commonly recognized as semantic in nature. Altogether, then, respondent seems to ineffectively employ both syntactic elaborations and, to the extent that it is attempted, two dimensions of semantic elaborations.

Scenario 4: Sixth grade student and teacher (in her first year if teaching) discussing a technique for fraction addition.

Student: Callie and me got the same answer, but we did it different ways.

Teacher: For what problem?

Student: We did $\frac{1}{2}-\frac{9}{6}$. We both got -1 for an answer.

Teacher: Let's see how you did it.

Student: Callie did:

$\frac{1}{2}+\frac{-9}{6}=\frac{3}{3} \cdot \frac{1}{2}+\frac{-9}{6}=\frac{3}{6}+\frac{-9}{6}=\frac{-6}{6}=-1$

I did: $\frac{1}{2}+\frac{-9}{6}=\frac{1+(-9)}{2+6}=\frac{-8}{8}=-1$. We both got -1 .

Teacher: Callie's technique is correct. Your technique is wrong.

Student: But we got the same answer.

Teacher: I think that you just got luck with your example. Most of the time, it won't work correctly.

Student: But if it works here, maybe it works on all kinds of problems. And it's easier to just add the tops and bottoms.

Teacher: But that does not always work. In fact, it rarely works.

Student: But maybe we should try it first and see if it works.

Teacher: But, if you try your way first and then have to try Callie's way to see if the answers are the same, this doubles your work. Just do it Callie's way.

Student: But my way is easier.

Teacher: Just do it Callie's way.

In the context of this brief student-teacher interaction, we reluctantly avoid commenting on the teacher's articulations and singularly focus on the student's communication. This student demonstrates whole number bias in the technique she employs toward incorrect fraction arithmetic strategies; these are both recognized as a syntactic (procedural) misunderstandings (Braithwaite, Pyke, \& Siegler, 2017; Bulgar, 2003; Charalambous \& Pitta-Pantazi, 2007; Gabriel et al., 2013; Siegler, Thompson, \& Schneider, 2011; Tirosh, 2000; Van Steenbrugge et al., 2014). Indeed, little semantic elaboration can be recognized in her work apart from some semblance of recognizing the notion of expected equality or equivalence.

Scenario 5: Sixth grade student and teacher (thirteen years teaching with seven years in this grade) discussing the lowest form of a fraction.

\section{Teacher: How can you tell if a fraction is simplified?}

Student: When the numerator and denominator are as small as possible. 
Teacher: The numbers 3 and 6 are pretty small. Is $\frac{3}{6}$ simp-
lified?

Student: No, it can be smaller.

Teacher: What can be smaller?

Student: $\frac{3}{6}$ can be made smaller to $\frac{1}{2}$.

Teacher: is $\frac{1}{2}$ less than $\frac{3}{6}$ ?

Student: No. It's not less than. They are equal. Just the top and bottom are smaller.

Teacher: Ok. Can we make $\frac{1}{2}$ into an equivalent fraction with a numerator and denominator less than 1 and 2?

Student: I don't think so.

Teacher: Which is less, 1 or -1 ?

Student: -1

Teacher: Which is less, 2 or -2?

Student: -2

Teacher: So, $\frac{-1}{-2}$ must be more simplified than $\frac{1}{2}$ ?

Student: No. We don't do that.

Teacher: I know that we don't usually do that. But I am wondering if my argument is sound.

Student: Since, -1 is smaller than 1 and -2 is smaller than 2 , I guess that $\frac{-1}{-2}$ can be more simplified than $\frac{1}{2}$. But we don't do that

Teacher: Then $\frac{-3}{-6}$ must be more simplified and $\frac{-30}{-60}$ must be more simplified and $\frac{-300}{-600}$ must be more simplified.

Student: That is silly. The numbers are getting bigger.

Teacher: Are they getting "bigger"?

Student: No, they are getting smaller, but looking bigger. Something is wrong.

Teacher: Well, let's go in another direction. Which is smaller, 1 or 0.1 ?

Student: 0.1 .

Teacher: Which is smaller, 2 or $0.2 ?$

Student: 0.2 .

Teacher: Then $\frac{0.1}{0.2}$ must be more simplified than $\frac{1}{2}$.

Student: We don't do that either. We don't put decimals in fractions.

Teacher: I agree that this is quite unusual. But is $\frac{0.1}{0.2}$ more simplified than $\frac{1}{2}$ ?

Student: Since $1 \div 10=0.1$ and $2 \div 10=0.2$, I think that $\frac{1}{2}=$ 0.1

0.2

Teacher: The question is not if they are equal. The question is whether the fraction with the smaller numerator and denominator is more simplified.

Student: If we use "smaller", then it is more simplified. But that isn't right.
Teacher: What isn't right?

Student: I think that the word "smaller" is causing the problem.

This student demonstrates unwavering semantic understanding of fraction equivalence, even when challenged with unusual questions. His communication reveals no commonly anticipated evidence of syntactic elaboration apart, possibly, from using problematic verbiage such as "smaller" and "bigger" numbers in respect to simplifying fractions and whole number bias in preferring natural numbers in the numerator and denominator over other rational number options. The limitation of the transcripts, however, do not provide sufficient evidence for other semantic elaborations apart, possibly, from recognizing magnitude or measurement among integers and decimal values.

Scenario 6: Seventh-grade students discussing simplifying fractions.

Teacher: Simplify the expression $\frac{86}{40}$.

Class: Most students produce $\frac{43}{20}$ or $2 \frac{3}{20}$.

Student 1: I think that it should be $\frac{215}{100}$.

Student 2: Why did you get that? All your numbers are bigger.

Student 3: I got 2.15. I divided on my calculator. That's simpler to do.

Student 4: But don't you need to keep it a fraction?

Student 1: I kept it as a fraction.

Student 2: But your numbers are all bigger. That's not simplifying.

Student 3: [To Student 1] Why did you get bigger numbers? What did you do?

Student 1: I wanted the bottom to be 100 . So, after I saw that $\frac{86}{40}$ is the same as $\frac{43}{20}$, I realized that 20 times 5 is 100. So, I multiplied the top by 5 also. So, $\frac{86}{40}$ became $\frac{43}{20}$ , which became 43 times 5 over 20 times 5 , or $\frac{215}{100}$.

Student 3: But why make the bottom into 100 , which is a bigger number?

Student 1: Because we have been making all our fractions into decimals and percents, I thought that if I made the bottom number 100, then when I could do this easier. Since $\frac{86}{40}$ is the same as $\frac{215}{100}$, that is the same as $215 \%$. And then, since percent means part of 100 and dividing by 100 means that I can just move the decimal place, I knew that $\frac{215}{100}$ is the same as 2.15 .

Student 3: Hey, that's what I got.

Student 1: So, $\frac{215}{100}$ was the easiest way for me to go from a fraction to percents to decimals.

Student 4: [To the teacher] Should we all make our fractions have 100 in the bottom?

Student 2: I want to keep doing it my way. It makes more sense to me if I simplify and get smaller numbers first. Then I can do what [Student 1] is doing. 
This brief interaction among numerous students demonstrates a greater number of dimensions of semantic and syntactic elaborations. For instance, syntactic elaboration may be recognized in: Students 2 and 3 mentioning "bigger" numbers, focusing on the numerator and denominator of the fraction and possibly employing whole number bias; Student 4 questioning if the simplification of a fraction remains a fraction; Student 3 immediately employing a calculator to convert the fraction to division; Student 3 focusing solely on the denominator of 100; Student 4 questioning if all fractions should be converted to denominators of 100; and Student 2 insisting on retaining a previously understood heuristic even if a novel one may be more valuable. However, some of these elaborations and others may also be recognized as semantic elaborations such as: Student 3 immediately using a calculator may be the result of recognizing the fraction as an operation or a quotient; Student 1 employing the notion of equivalence to recognize that $\frac{86}{40}=\frac{43}{20}=\frac{215}{100}$; and Student 1 connecting $\frac{215}{100}$ to $215 \%$ and 2.15 .

\section{Discussion and Implications}

As previously mentioned, this study expanded upon the common notion of semantic and syntactic elaboration of fractions. Herein, semantic elaborations of fractions include the subconstructs of ratio, operator, quotient, measure, and part-whole together with fraction equivalence and syntactic elaborations include whole number bias, incorrect fraction operation strategies, and errors associated with division of two fractions (Behr et al., 1983; Braithwaite et al., 2017; Bulgar, 2003; Charalambous \& Pitta-Pantazi, 2007; Gabriel et al., 2013; Kieren, 1976; Siegler, Thompson, \& Schneider, 2011; Tirosh, 2000; van Steenbrugge et al., 2014). With these dimensions in place, it was possible to analyze fourth through sixth grade student work and communication through the lens of semantic versus syntactic elaboration.

Consistent with Hallett, Nunes, and Bryant (2010), it was revealed that individual students tend to employ semantic elaboration to a greater or lesser extent than syntactic elaboration. However, it may be overly simplistic to state that students do better when they more frequently employ semantic elaborations. While some have noted that limited conceptual (semantic) knowledge of fractions hinders fraction learning (Byrnes \& Wasik, 1991; Kerslake, 1986; Rittle-Johnson, Siegler, \& Alibali, 2001) and that conceptual knowledge regarding fractions is a prerequisite for correctly performing fraction arithmetic, Kerslake (1986) argues that students can solve some fraction problems primarily using procedural knowledge with only limited conceptual understanding and Rittle-Johnson Siegler, and Alibali (2001) note that conceptual and procedural (syntactic) knowledge grow and develop simultaneously, supporting each other as they develop. Indeed, Hallett Nunes, and Bryant (2010) note that students often combine conceptual and procedural knowledge. This was observed in student participant work in this study, as some students exhibited aspects of both semantic and syntactic understanding.

While a goal of education may be to develop student semantic fraction understanding, we may not yet fully know the extent to which semantic and syntactic understanding complement, rather than compete with, each other. In this study we considered student's preferences toward one elaboration over another. Left uninvestigated is the interplay of these elaborations. This is left for future research.

However, best revealed through Scenario 6, interpreting a student's use of semantic or syntactic elaboration may be more complex than previously revealed. Indeed, articulations must be carefully interpreted from the context of the scenario at play as well as through the sequence of articulations among the interloculars. This reveals that far more research is needed in this realm in the future. The most significant implication of this study may be that, in the context of fraction learning, some students seemingly employ aspects of both semantic and syntactic elaborations. Thus, as previously stated, it may be that these forms of elaborations should be considered as complementary rather than as oppositional. Teachers may learn to value both types of elaborations rather than have as a singular goal that all students perform primarily semantic elaborations (conceptual understanding).

Notably, this study focused on student learning and not on teaching. Unfortunately, this study cannot make a claim regarding teaching techniques that might either increase student semantic elaboration or help students blend semantic and syntactic elaborations in the context of fraction learning or learning in any other mathematical domain. Indeed, this study makes no claims that any particular pedagogy might accomplish this. Thus, an implication from this study may be the need to investigate these pedagogies. However, the authors hope that this is done with caution. Attempting to construct a curriculum that enhances semantic elaborations for all may diminish the recognition that all students may balance semantic and syntactic elaborations differently. Altogether, much more research is needed in this area. We welcome others to join us in this investigation.

\section{References}

Bartelet, D., Ansari, D., Vaessen A., Blomert, A. (2014) Cognitive subtypes of mathematics learning difficulties in primary education. Research in Developmental Disabilities 35, 657-670.

Baroody, A. J., \& Hume, J. (1991). Meaningful mathematics instruction: The case of fractions. Remedial and Special Education, 12(3), 54-68.

Behr, M., Lesh, R., Post, T., \& Silver, E. (1983). Rational number concepts. In R. Lesh \& M. Landau (Eds.), Acquisition of Mathematics Concepts and Processes, (pp. 91-125). New York, NY: Academic Press.

Bogdan, R. C., \& Biklen, S. K. (2003). Qualitative research for education: An introduction to theories and methods (4th ed.). Boston: Allyn and Bacon.

Braithwaite, D. W., Pyke, A. A., \& Siegler, R. S. (2017). A computational model of fraction arithmetic. Psychological Review, 124(5), 603-625.

Bulgar, S. (2003) Children's' sense-making of division of fractions. Journal of Mathematical Behavior, 22(3), 319-334.

Byrnes, J. P., \& Wasik, B. A. (1991). Role of conceptual knowledge in mathematical procedural learning. Developmental Psychology, 27(5), 777-786.

Charalambous, C. Y. \& Pitta-Pantazi, D. (2007) Drawing on a theoretical model to study students' understandings of fractions. Educational Studies in Mathematics, 64(3), 293-316.

Creswell, W. J. (2003). Research design: Qualitative, quantitative and mixed methods approaches (2nd ed.). London: Sage Publications.

D'Ambrosio, B. S., \& Spangler Mewborn, D. (1994) Children's constructions of fractions and their implications for classroom instruction. Journal of Research in Childhood Education, 8(2), 150-161. 
DeWolf, M., Rapp, M., Bassok, M. and Holyoak, K. J. (2014) Semantic alignment of fractions and decimals with discrete versus continuous entities: A textbook analysis. Proceedings of the Annual Meeting of the Cognitive Science Society, 36, 2133- 2138.

Duval, R. (2006). A cognitive analysis of problems of comprehension in a learning of mathematics. Educational Studies in Mathematics, 61, 103-131.

Gabriel, F., Coché, F., Szucs, D., Carette, V., Rey, B., \& Content, A. (2013). A componential view of children's difficulties in learning fractions. Frontiers in Psychology, 4, 715 - 750.

Goldin, G. A. (2000). A scientific erspective on structure: task-based interviews in mathematics education research. In A. Kelly \& R. Lesh (Eds.), Handbook of Research Design in Mathematics and Science Education (pp. 517-546). Mahwah, NJ: Lawrence Erlbaum Associates.

Hallett, D., Nunes, T., \& Bryant, P. (2010). Individual differences in conceptual and procedural knowledge when learning fractions. Journal of Educational Psychology, 102(2), 395-406.

Halliday, M. A. K. (1975). Learning how to mean: Explorations in the Development of Language. London: Edward Arnold.

Halliday, M. A. K. (1993). Towards a language-based theory of learning. Linguistics and Education, 5(2), 93-116.

Halliday, M. A. K., Mclntosh, A., \& Strevens, P. (1964). The Linguistic Sciences and Language Teaching. London: Longmans.

Hyde, D. C., Khanum, S., \& Spelke, E. S. (2014). Brief nonsymbolic, approximate number practice enhances subsequent exact symbolic arithmetic in children. Cognition, 131, 92-107.

Inglis, M., \& Gilmore, C. (2013). Sampling from the mental number line: How are approximate number system representations formed? Cognition, 129, 63-69.

luculano, T. \& Butterworth, B. (2011). Rapid communication Understanding the real value of fractions and decimals. The Quarterly Journal of Experimental Psychology, 64(11), 2088-2098.

Jacob, S. N., \& Nieder, A. (2009). Notation-independent representation of fractions in the human parietal cortex. The Journal of Neuroscience, 29(14), 46524657.

Kallai, A.Y., \& Tzelgov, J. (2009). A generalized fraction: An entity smaller than one of the mental number line. Journal of Experimental Psychology: Human Perception and Performance, 35(6), 1845-1864.

Kaput, J. J. (1987a). Representation systems and mathematics. In C. Janvier (Ed.), Problems of Representation in Teaching and Learning Mathematics (pp. 19-26). Hillsdale, NJ: Erlbaum.

Kaput, J. J. (1987b). Toward a theory of symbol use in mathematics. In C. Janvier (Ed.), Problems of representation in mathematics learning and problem solving (pp. 159-195). Hillsdale, NJ: Erlbaum.

Kara, F. \& Incikabı, L. (2018). Sixth Grade Students' Skills of Using Multiple Representations in Addition and Subtraction operations in Fractions. International Electronic Journal of Elementary Education, 10(4),
463-474.

Kerslake, D. (1986). Fractions: Children's Strategies and Errors. A Report of the Strategies and Errors in Secondary Mathematics Project. Windsor, England: NFER-Nelson.

Kieren, T. E. (1976). On the mathematical, cognitive, and instructional foundations of rational numbers. In R. A. Lesh \& D. A. Bradbard (Eds.), Number and Measurement. Papers from a Research Workshop (pp. 101-144). Columbus, OH: ERIC.

Kolkman, M.E., Kroesbergen, E.H., \& Leseman, P.P.M. (2013). Early numerical development and the role of non-symbolic and symbolic skills. Learning and Instruction, 25, 95-117.

Leibovich, T. \& Ansari, D. (2016). The symbol-grounding problem in numerical cognition: A review of theory, evidence, and outstanding questions. Canadian Journal of Experimental Psychology, 4, 1196-1961.

Lyons, I. M., Price, G. R., Vaessen, A, Blomert, L., \& Ansari, A. (2014). Numerical predictors of arithmetic success in grades 1-6. Developmental Science, 10, 1-11.

Meert, G., Grégoire, J., \& Noël, M.-P. (2009). Rational numbers: Componential versus holistic representation of fractions in a magnitude comparison task. The Quarterly Journal of Experimental Psychology, 62(8), 1598-1616.

Miles, M. B. \& Huberman, M. N. (1994). Qualitative data analysis: an expanded sourcebook. Thousand Oaks, CA: Sage.

Murray, H., Olivier, A., \& Human, P. (1996). Young students' informal knowledge of fractions. In L. Puig \& A. Gutiérrez (Eds.), Proceedings of the Twentieth Conference of the International Group for the Psychology of Mathematics Education, (4, 43 - 50). Valencia, Spain.

Newstead, K. and Murray, H. (1998). Young students' constructions of fractions. In A. Olivier \& K. Newstead (Eds.), Proceedings of the Twentysecond International Conference for the Psychology of Mathematics Education: Vol. 3. (pp. 295-302). Stellenbosch, South Africa.

Opfer, J. E., \& DeVries, J. M. (2008). Representational change and magnitude estimation: Why young children can make more accurate salary comparisons than adults. Cognition, 108, 843-849.

Park, J., \& Brannon, E. M. (2013). Training the approximate number system improves math proficiency. Psychological Science, 24, 2013- 2019.

Park, J., \& Brannon, E. M. (2014). Improving arithmetic performance with number sense training: An investigation of underlying mechanism. Cognition, $133,188-200$

Rittle-Johnson, B., Siegler, R. S., \& Alibali, M. W. (2001). Developing conceptual understanding and procedural skill in mathematics: An iterative process. Journal of Educational Psychology, 93(2), $346-362$.

Sasanguie, D., Gobel, S.M., Moll, K., Smets, K., \& Reynvoet, B. (2013). Approximate number sense, symbolic number processing, or number-space mappings: what underlies mathematics achievement? Journal of Experimental Child Psychology, 114(3), 418-431. 
Schleppegrell, M. J. (2007). The linguistic challenges of mathematics teaching and learning: A research review. Reading \& Writing Quarterly, 23(2), 139-159.

Schneider, M., \& Siegler, R. S. (2010). Representations of the Magnitudes of Fractions. Journal of Experimental Psychology: Human Perception and Performance, 36, 1227-1238.

Schulze, J. M. (2016). Understanding the developing persuasive writing practices of an adolescent emergent bilingual through systemic functional linguistics: A case study. International Journal of Learning, Teaching and Educational Research, 15(10), 163-179.

Siegler, R. S., Duncan, G. J., Davis-Kean, P. E., Duckworth, K., Claessens, A., Engel, M.,Chen, M. (2012). Early predictors of high school mathematics achievement. Psychological Science, 23(10), 691697.

Siegler, R. S., Thompson, C. \& Schneider, M. (2011) An integrated theory of whole number and fractions development. Cognitive Psychology, 62(4), 273-296.

Stafylidou, S. \& Vosniadou, S. (2004) The development of students' understanding of the numerical value of fractions. Learning and Instruction, 14(5), 503-518.

Streefland, L. (1991). Fractions in realistic mathematics education: A paradigm of developmental research. Springer Science \& Business Media.

Strauss, A., \& Corbin, J. (1990). Basics of Qualitative Research. London: Sage Publications Ltd.

Thwaite, A. (2015). Pre-service teachers linking their metalinguistic knowledge to their practice: $A$ Functional Approach. Functional Linguistics, 2(1), $1-17$.

Tirosh, D. (2000). Enhancing prospective teachers' knowledge of children's conceptions: the case of division of fractions. Journal for Research in Mathematics Education, 31(1), 5-25.

Turkan, S., de Oliveira, L. C., Lee, O., \& Phelps, G. (2014). Proposing a knowledge base for teaching academic content to English language learners: Disciplinary linguistic knowledge. Teachers College Record, 116(3), 1-30.

van Lier, L., \& Walqui, A. (2012). Language and the Common Core State Standards. Commissioned paper by the Understanding Language Initiative. Stanford, CA: Stanford University. Retrieved from http://ell. stanford.edu/papers/language

Van Steenbrugge, H., Lesage, E., Valcke, M., \& Desoete, A. (2014). Preservice elementary school teachers' knowledge of fractions: a mirror of students' knowledge? Journal of Curriculum Studies, 46(1), 138-161.

Wodak, R. \& Meyer, M. (2009). Methods for Critical Discourse Analysis. SAGE 